\title{
Punitive Sanctions and the Transition Rate from Welfare to Work
}

\author{
Gerard J. van den Berg, Free University Amsterdam, \\ Tinbergen Institute, IFAU-Uppsala, INSEE-CREST, and Centre \\ for Economic Policy Research (CEPR) \\ Bas van der Klaauw, Free University Amsterdam, \\ Tinbergen Institute, Scholar, and CEPR
Jan C. van Ours, Tilburg University, Center of Economic Research (CentER), and CEPR

In the Netherlands, the average exit rate out of welfare is dramatically low. Most welfare recipients have to comply with guidelines on job search effort that are imposed by the welfare agency. If they do not, then a sanction in the form of a temporary benefit reduction can be imposed. This article investigates the effect of such sanctions on the transition rate from welfare to work using a unique set of rich register data on welfare recipients. We find that the imposition of sanctions substantially increases the individual transition rate from welfare to work.

We are grateful to the Welfare Agency (Dienst Sociale Zaken en Werkgelegenheid) of Rotterdam, and to Daan Spannenberg in particular, for kindly providing the data. We thank David Grubb, Jeff Smith, and Maarten Lindeboom for useful comments, and Michael Keane for useful information on the U.S. welfare system. Financial support from the Netherlands Ministry of Social Affairs and Employment is gratefully acknowledged. Contact the corresponding author, Bas van der Klaauw, at Klaauw@tinbergen.nl.

[Journal of Labor Economics, 2004, vol. 22, no. 1]

(C) 2004 by The University of Chicago. All rights reserved. 0734-306X/2004/2201-0008\$10.00 


\section{Introduction}

In the United States, welfare is typically used to support single-parent households, whereas in European countries it is also often used to support long-term unemployed workers. Welfare (or "social assistance") then acts as a safety net for those unemployed workers who are not entitled to any other social security benefits like unemployment insurance or disability benefits. Whatever their designs, exit rates out of welfare are low, and the current welfare systems are subject to criticism (see, e.g., Gueron 1990; Moffitt 1992).

In principle, a large range of policy measures is available to prevent unemployed individuals from becoming dependent on welfare and to stimulate and assist the long-term unemployed workers in their search for jobs. Examples are subsidized employment for youth and long-term unemployed workers, training and schooling programs, special public employment services, and punitive benefit reductions. In this article we evaluate the effect of sanctions that are imposed if the welfare recipient

does not comply with the minimum job search requirements and rules of registration laid out by the welfare agency. In particular, we evaluate the effect of a sanction on the duration until exit into work. A sanction consists of a temporary reduction of the welfare benefits level. The duration and size of the reduction depend on the nature of the infringement. Reasons for imposition of sanctions can be insufficient job search activity, fraud, unnecessary job loss, and lack of willingness to participate in education or training programs (below we examine this in more detail). In the Netherlands, before 1992, sanctions were hardly ever used. However, by the mid-1990s, about $5 \%$ of the welfare recipients in a given year received a sanction. It should be noted that, in the Netherlands, the state guarantees the provision of a minimum income to each citizen in urgent financial need. This effectively restricts the magnitude of sanctions in welfare, and indeed it creates an upper bound on the harshness of a system with sanctions. As a result, the duration and size of the benefit reductions are relatively low in comparison with those for unemployment insurance (UI) recipients. Most welfare sanctions are only for 1 or 2 months, and the maximum reduction of the welfare benefit is $20 \%$.

It is important to stress that there is a difference between (i) the duration effect of the actual imposition of a sanction and (ii) the duration effect of having a welfare system with sanctions as opposed to a welfare system without sanctions. The second effect, which is a preventive or ex ante effect, is positive if the mere threat of sanctions stimulates the transition from welfare to work. Our data are from a world with sanctions, so our reduced-form empirical analysis of microduration data cannot be used to evaluate the magnitude of this ex ante effect. The benefit reduction involved in the ex post effect probably makes the individual more prone 
to accept jobs and search more intensively. However, a sanction is more than just a mechanical temporary reduction in benefits. The sanction is induced by a failure to meet certain job search requirements, and the welfare agency will explain its decision to the individual. Furthermore, individuals are closely monitored after a sanction, so they have an incentive to comply with the search requirements in order to prevent additional punishments. All this is likely to increase the search intensity of the individual from the moment at which the sanction is imposed onward. ${ }^{1}$ In sum, the imposition of a sanction is expected to increase the transition rate from welfare to work.

The empirical analysis in the present study resembles the approach developed in Abbring, Van den Berg, and Van Ours (1997) for analyzing the effect of sanctions in UI on the transition rate to work. ${ }^{2}$ The main problem concerns the endogenous selection involved in the imposition of sanctions. It is clear that sanctions are imposed by the welfare agency in response to the behavior of the welfare recipient. Welfare recipients who get a sanction are most likely different from other welfare recipients. Neglecting this gives a biased estimate of the sanction effect. Therefore, we model both the process by which welfare recipients get a sanction and the process by which they leave unemployment. The two processes are allowed to be interdependent by way of their unobserved determinants and by way of a direct effect of a realized sanction on the transition rate to employment (this approach is similar to that used by Gritz [1993] and Bonnal, Fougère, and Sérandon [1997] in their studies on training effects). We allow the rate at which a sanction is imposed to depend on observed explanatory variables, on the elapsed unemployment duration, and on unobserved determinants. For the duration dependence we take a flexible piecewise constant specification. The transition rate from welfare to work is modeled in a similar way, with the qualification that one of its explanatory variables depends on whether a sanction has been imposed. We

${ }^{1}$ There is evidence that an increase in search intensity increases the transition rate from unemployment to employment (see Devine and Kiefer [1991] for a survey). Dolton and O'Neill (1996) and Gorter and Kalb (1996) estimate the effect of interviews that are supposed to provide advice and counseling to UI recipients. Both find a positive and lasting effect on the transition rate from unemployment to employment. Meyer (1995) finds significant effects of similar treatments in experiments across the United States ("search experiments"). By contrast, Ashenfelter, Ashmore, and Deschênes (2003) do not find any effect of closer monitoring. However, it should be noted that they study UI recipients with relatively good labor-market prospects.

${ }^{2}$ Obviously, the populations of UI and welfare recipients are very different in terms of their background and their opportunities. The UI recipients have better labor-market prospects, since they necessarily have a substantial amount of recent work experience. Also, UI benefits are usually higher than welfare benefits. See also Sec. IIA. 
identify the causal effect of a sanction on the transition rate from welfare to work by exploiting the information in the timing of the events we observe (imposition of a sanction or exit to work).

The outline of this article is as follows: Section II gives a detailed description of the Dutch welfare system. We discuss the eligibility requirements for receiving welfare, the guidelines with which a recipient must comply, the sanctions for noncompliance, and the way that sanctions are actually imposed. In Section III, we discuss the empirical model that is inspired by job search theory. Section IV discusses the unique database we use to estimate the model. This database covers all unemployed individuals who started to collect welfare benefits in Rotterdam in 1994 and contains information about them until they left the welfare system or until October 1996, whichever was first. In Section V we present the estimation results, and we perform some sensitivity analyses. Section VI concludes.

\section{Welfare Recipients in the Netherlands}

\section{A. Theoretical Framework}

In this section we describe some institutional aspects of the Dutch welfare (or "social assistance") system in the mid-1990s. It is not our intention to give an exhaustive description of the system. Instead, we explain the basic structure and highlight aspects that are relevant for our purposes. We rely on some publications in Dutch on welfare in the Netherlands (Angenent, Bommeljé, and Schep 1993, 1994; Angenent and den Heeten 1995).

The Netherlands has about 16 million inhabitants, of which 6 million are employed workers. The aim of welfare is to support people without income who are not entitled to any other social security benefits. In addition, the individual must (i) be legally allowed to stay in the Netherlands and (ii) be over 18 years old. In 1994, 485,000 individuals without work received welfare benefits. Of these, 320,000 are counted as unemployed; these people have a formal obligation to search for a job. The remaining 165,000 individuals received welfare benefits without an obligation to search for a job. Of the latter group, $55 \%$ belong to a singleparent household with children below 12 years of age (welfare for the latter type of individuals is similar to the old Aid to Families with Dependent Children [AFDC] program in the United States). ${ }^{3}$ In the sequel we ignore the recipients who do not have an obligation to search for a

${ }^{3}$ Aid to Families with Dependent Children has currently been replaced by Temporary Aid to Needy Families (TANF). The main difference is that in the new system claimants receive benefits only for a fixed period. Another difference is that TANF is decentralized, while AFDC was organized on the federal level. Under TANF, states can more or less construct their own welfare program. 
job, since both the rate of getting a sanction and the transition rate to work are determined in a very different way than for the other recipients. For simplicity we will use the term "welfare recipient" to denote just those recipients who have an obligation to search for a job and who are counted as unemployed.

The welfare benefits level can be decomposed into a basic level and a series of bonuses. The basic level is fully determined by the household composition and by the extent to which other sources of income and assets are available. Thus, welfare benefits are means tested. If the applicant has a partner with a sufficiently high income out of labor, or if the applicant has a sufficiently high amount of assets (like a house), then in general he does not qualify for welfare. Concerning the level of benefits, one may distinguish between four household categories. ${ }^{4}$ In 1995, the net benefits level was about 1,800 Dutch guilders per month for a two-parent family (i.e., a married couple with or without children), about 1,600 for a single-parent family, about 1,250 for a single individual over 23 years of age, and about 900 for a single individual below 23 years of age. The net replacement rates on welfare in 1995 were $62 \%$ for a single individual, $74 \%$ for a married couple without children, $80 \%$ for a married couple with two children, and $72 \%$ for a single individual with two children. ${ }^{5}$ These are slightly higher than the replacement rates on welfare in most other European countries and much higher than those in the United States (for a more extensive discussion on these replacement rates, see OECD [1997]).

Municipalities have power to provide bonuses on top of the basic benefits level. For example, some municipalities pay bonuses for the use of sports facilities and public transport or for health-related expenses like glasses. The types of bonuses, the rules on entitlement to a bonus, and the levels of the bonuses vary considerably across municipalities. ${ }^{6}$

In 1994 , about $35 \%$ of the welfare recipients had been collecting welfare benefits for an uninterrupted duration of more than 3 years. Of the welfare recipients, $68 \%$ are single, $25 \%$ are married, and only $7 \%$ belong to a single-parent family. Welfare recipients often have low skills. The fraction of individuals with primary education is $15 \%$ for the whole labor force

${ }^{4}$ There are a few other cases that are less common; see, e.g., Van Andel and Bommeljé (1996).

${ }^{5}$ These replacement rates are relative to the net earnings of the average productivity worker, which is a worker with average earnings (OECD 1997).

${ }^{6}$ This provides an incentive for welfare recipients to move to other municipalities. However, the housing market for lower-income households is highly regulated, and in many municipalities the average waiting time for a house is very long, in particular if there are no household members with a job in that municipality. Since we only have data on recipients in the municipality of Rotterdam, we cannot exploit this feature to define a natural experiment. 
but $35 \%$ for welfare recipients. The age structure of the population of welfare recipients is about the same as that in the labor force.

One may distinguish between two types of individuals among the unemployed welfare recipients. The first are workers who enter unemployment after leaving full-time education. The second are job losers, that is, workers with a history of labor-force attachment. The workers in this latter group have either run out of eligibility for UI benefits or have never collected UI benefits because they did not meet eligibility criteria at the start of their unemployment spell. The maximum duration of UI depends on the employment history of the individual and ranges from 6 months to 4.5 years. Note that the individuals entering welfare from UI are a selective sample of the inflow into UI. On average, the more disadvantaged individuals eventually move to welfare. In the inflow into welfare, the group of school leavers is much smaller than the group of job losers $(10 \%$ vs. $90 \%)$. There is also a large difference between the exit rates of the two groups $(65 \%$ and $35 \%$, respectively, within 1 year; it should be noted that most welfare recipients under 21 years of age participate in youth job guarantee programs after having been on welfare for 6 months). In this study we restrict attention to the second group of welfare recipients, the job losers. These are more important both from a quantitative point of view (a large fraction of the inflow into welfare) and from a qualitative point of view (a small exit rate out of welfare), and it is obvious that the behavior in the two groups cannot be captured in a single model. In the remainder of the article we refer to this second group as the welfare recipients, thereby omitting the qualification of them being job losers.'

A welfare recipient has several obligations in order to remain eligible for a benefit: he has to (i) prevent unnecessary job loss; (ii) take actions to prevent him from staying unemployed, so he has to search for a job and accept appropriate job offers, register at the public employment office, participate in education and training, and so on; and (iii) keep the welfare agency informed about everything that is relevant to the payment of welfare benefits. The exact guidelines may be determined by the municipalities. However, most municipalities have not formulated strict rules and leave some room for the discretion of the caseworker. Therefore, the rules to which the welfare recipients must comply do not only vary between municipalities but also between caseworkers of the welfare agency.

Although welfare recipients are obliged to search for a job, not all of them seem to be willing to work. A survey on attitudes of welfare recipients reveals that about $10 \%$ of the welfare recipients state that they do not want to have a job. The $90 \%$ that do want to work are not always eager to find a job (Angenent et al. 1994). Only 55\% indicate that they

${ }^{7}$ Three-quarters of the group of job losers did not collect unemployment insurance benefits before entering welfare, and one-quarter did. 
are actively searching for a job. Furthermore, a lot of workers only accept a job if the net wage is at least 250 Dutch guilders per month above the welfare benefits level. Finally, half of the welfare recipients indicate that they do not want to move if that is required for a new job.

\section{B. Empirical Model}

Sometimes sanctions are imposed to punish welfare recipients because of administrative reasons like returning late from holiday, filling in forms incorrectly, and so on. Nevertheless, the main reason to impose sanctions is noncompliance with job search guidelines. Previous studies on the Dutch welfare benefit system argued that sanctions cannot affect the transition rate from welfare to work (Angenent et al. 1993). Their argument runs as follows: since welfare recipients have a weak labor market position, sanctions only induce apparent changes in behavior. Sanctioned welfare recipients or recipients at risk signal an increased search intensity while in reality they do not make an additional effort. For example, a welfare recipient may show the welfare officer fake application letters or may perform "negative" applications by acting during an application interview in such a way as to minimize the probability of being hired. The worker transmits signals of lack of interest to the employer while at the same time appearing that he is complying with job search guidelines. ${ }^{8}$

The procedure of imposing a sanction consists of two steps. In the first step, it is established that a welfare recipient is not complying with the guidelines of the welfare agency. Information on possible offenses can come from the monthly form a welfare recipient has to fill in or from conversations between the employees of the welfare agency and the welfare recipient. It is also possible that the public employment office informs the welfare agency about a lack of job search activity. Many cases of noncompliance are established in the so-called reinvestigation, which is a standard procedure of evaluating the welfare recipient's behavior that usually takes place around 8 months after the start of collecting the welfare benefits.

In the second step of the sanction procedure, it is decided whether the noncompliance will be punished. Noncompliance does not always lead to a sanction. ${ }^{9}$ Local or district governments are responsible for the payment of welfare benefits, but the national government has set binding

\footnotetext{
${ }^{8}$ A strategy in which individuals take a job on imposition of a sanction, and quit immediately in order to make a "fresh start" in UI, would not be optimal: the individual would probably not be entitled to UI benefits, because the recent history of labor-force attachment was too short. If, however, the individual would meet the requirements for UI, it would be reduced immediately after quitting because of "lack of action to prevent job loss" (see Abbring et al. 1997).

${ }^{9}$ However, in case of severe fraud, the welfare agency may decide to pursue legal prosecution.
} 
rules and procedures concerning the imposition of sanctions. However, these rules do not imply that the sanctions are imposed automatically or fully objectively. The caseworkers of the welfare agency have some discretion to interpret the rules. According to the procedures, the decision to impose a sanction on a particular welfare recipient is taken by the local welfare employee after consulting a so-called decision maker. The decision maker checks the proposal to make sure that all the right legal steps in the procedure have been taken. The employee of the welfare agency takes the state of the local labor market into account when deciding whether a sanction should be imposed. Furthermore, conditional on noncompliance with the guidelines, the decision to impose a sanction also depends on characteristics of the welfare recipients like attitude, appearance, and motivation (Angenent et al. 1993). These are all characteristics that are unobserved by the researcher trying to investigate the effect of sanctions. A 1992 investigation of 3,500 personal files shows that, even though noncompliance was established for approximately $10 \%$ of the welfare recipients, only about $5 \%$ did get a sanction. Noncompliance is more common among young welfare recipients. And, conditional on noncompliance, younger welfare recipients are more likely to get a sanction imposed. This may be because of the better labor-market position of younger workers. Less-educated workers more often do not obey the search rules, but conditional on this they are less likely than more-educated workers to get a sanction imposed. Again, the bad labor-market position of lesseducated workers may explain the difference. In Section V we examine whether these results are confirmed by our multivariate analysis.

Once a sanction has been imposed, the welfare agency provides the welfare recipient with some assistance on how to improve his behavior in order to avoid future sanctions, and on how to search for jobs more effectively. At the same time the behavior of the welfare recipient is more closely monitored. If a sanction is imposed because of insufficient job search activity, then the welfare agency is obliged to reexamine the job search activities of the welfare recipient within 3 months after the imposition. (If a sanction is imposed for other reasons, then the welfare agency is not obliged to do so, although it often does.) Based on the outcome of the renewal examination, the welfare agency may decide to renew the sanction or punish the welfare recipient with a higher sanction. Our data show that in practice sanctions are almost never renewed.

The period between the establishment of noncompliance by the welfare agency caseworker and the imposition of a sanction is usually 1-2 months. In rare cases it may take years before noncompliance is established. This may happen if there are investigations done solely through the mail with respect to the behavior of the welfare recipient.

Now let us examine the two most important features of a sanction: its magnitude and its duration. These depend on the nature of the infringe- 
ment and the extent to which a welfare recipient can be held responsible for the infringement. There are general guidelines for the imposition of sanctions, but again the welfare agency may take individual circumstances of the welfare recipient into account. As explained in Section I, the magnitude and the duration of the benefits reductions are limited. The reduction is either $5 \%, 10 \%$, or $20 \%$ of the benefits level. The duration of the reduction can be up to 6 months but is usually only 1 or 2 months. According to the official guidelines, there are four categories of sanctions: (i) if a welfare recipient does not register or renew his registration at a public employment office, a benefit reduction of $5 \%$ during 1 month is recommended. (ii) A sanction of $10 \%$ during 1 month is recommended if a welfare recipient insufficiently searches for a job, neglects appointments at the welfare agency, and does not cooperate in the search for appropriate training programs. (iii) If the welfare recipient's behavior interferes with searching for a job or if he refuses training, a sanction can be imposed with a reduction of $20 \%$ during 1 month. (iv) A benefit reduction of $20 \%$ during 2 months is recommended if the welfare recipient refuses an appropriate job offer or did not prevent unnecessary job loss prior to entering welfare.

\section{The Model}

\section{A. Theoretical Framework}

Our empirical model specification is motivated by a theoretical job search model framework in which punitive sanctions are incorporated. Abbring et al. (1997) formally develop a basic version of such a model. Here we describe a more general framework, taking into account that we consider welfare rather than UI. Subsequently, we discuss the empirical model, and at the end of Section III we discuss the parameterization of our model.

The point of departure is the basic job search model with endogenous search effort $s$ as presented by, for example, Mortensen (1986). Consider an unemployed individual who searches sequentially for a job. Given a particular search intensity $s$, job offers arrive according to the rate $\lambda(s)$, with $\lambda(\mathrm{s})$ increasing in $s$. The individual is able to choose $s$. Offers are random drawings from a wage offer distribution $F(w)$. Every time an offer arrives the decision has to be made whether to accept it or reject it and search further. Once a job is accepted, it will be held forever at the same wage. During unemployment, a flow of benefits $b$ is received, and a flow of search costs $c(s)$ has to be paid, with $c(s)$ increasing in $s$, and with $b$ possibly including a nonpecuniary utility of being unemployed. The individual aims at maximization of the expected present value of income over an infinite horizon, with discount rate $\rho$. It is well known that in this model the optimal strategy of unemployed individuals can be char- 
acterized by a reservation wage $\phi$ (giving the minimal acceptable wage offer) and an optimal search intensity $s$.

We now introduce sanctions in this framework. We start by assuming that sanctions are equivalent to temporary benefit reductions imposed at a certain rate depending on $s$. We then increase the degree of realism of the model by incorporating other features of the sanctions system.

It is useful to distinguish between sanctions as an institutional aspect of the environment of the individual, and the actual imposition of a sanction for an individual. Concerning the former, one may argue that the mere threat of a sanction should suffice to prevent it from ever being enforced. It is clear that the data contradict such a view. Alternatively, one may argue that the moment of occurrence of a sanction is perfectly foreseen by the benefits recipient and is taken into account in determining his choices. The data and the results of this article as well as the institutional aspects of the welfare system (see Sec. II) contradict this view as well. There is variation across individuals in the strictness with which the rules are applied, and presumably there is a certain degree of randomness in this (this is confirmed by field research; see the references in the previous section). We conjecture that the individual does not exactly know the rules with which he has to comply and that he does not exactly know what type of behavior will generate a sanction; even if he knows he is under risk, then he does not know when a sanction will be imposed. It is plausible, however, that the individual does know the relation between his behavior and the probability that a sanction will be imposed. Some individuals will be more willing to take the risk of being given a sanction than others (e.g., because they have a higher nonpecuniary utility of being unemployed). We therefore assume that, from the point of view of an unemployed individual, there is a rate $p(s)$ at which a sanction is imposed, with $p(s)$ decreasing in $s$. We assume that the individual knows the relationship between $s$ and $p(s)$, but he does not know in advance when a sanction will be imposed. It may actually be realistic to have $p(s)=0$ for all $s$ 's exceeding a certain threshold value. This threshold value can be interpreted as the explicit minimum requirements on job search by the welfare agency. Suppose that the function $p(s)$ and all other structural parameters are constant over the welfare duration. Then the optimal reservation wage $\phi$ and search intensity $s^{*}$ of an individual who is not currently punished can be expressed as functions,

$$
\begin{aligned}
\phi & =\phi[b, c(.), \lambda(.), p(.), F(.), \rho, \mathcal{P}] \\
s^{*} & =s^{*}[b, c(.), \lambda(.), p(.), F(.), \rho, \mathcal{P}],
\end{aligned}
$$

where $\mathcal{P}$ denotes the structural parameters that prevail after imposition of a sanction (notably, the lower level of $b$ ). The corresponding transition 
rate from welfare to work $\theta_{u}$ equals $\lambda\left(s^{*}\right)[1-F(\phi)]$, and the sanction rate $\theta_{s}$ equals $p\left(s^{*}\right)$.

Since the welfare recipient does not anticipate the actual moment of imposition of a sanction, the sanction causes a downward shift in the reservation wage of the welfare recipient at the moment of imposition. At the same time, the welfare recipient increases his search effort since the lower benefit level makes it less attractive to be unemployed. Therefore, at the moment at which a sanction is imposed, the transition rate from welfare to work jumps upward. These effects are temporary. The welfare recipient knows the duration of the sanction and anticipates the moment at which the sanction period expires. As the moment of expiration of the sanction approaches, therefore, his reservation wage increases and his search effort decreases. At the moment that the period of benefit reduction ends, both the reservation wage and the search effort are at the level that would prevail if no sanction had been imposed.

A comparison of a system without sanctions to a system with sanctions entails a comparison of the model outcomes with $p(s) \equiv 0$ to the outcomes above. It is not difficult to show that $\theta_{u}$ is smaller in the former system than in the latter system before a sanction is actually imposed. This holds for all individuals who have a positive probability of getting a sanction in the latter system.

Now consider the more realistic kind of sanction that includes additional job search assistance and closer monitoring. In most cases the welfare agency reexamines the job search activities of the welfare recipient 3 months after imposition of the sanction. Because of the closer monitoring, the punished individual has an incentive to comply with the search requirements in order to prevent future and additional punishments. This increases the search intensity and reduces the reservation wage beyond the period of benefits reduction. (Our data show that recidivism is rare; see Sec. IV.) The search assistance may also consist of the provision of additional information on the search requirements. It could be that welfare recipients had an imprecise idea of the relationship between $s$ and $p(s)$. In terms of a threshold value, this would mean that welfare recipients knew that there was a threshold in $s$ above which $p(s)=0$, but they did not know its exact position. After getting a sanction they may adjust their estimate of the threshold value in an upward direction. As a result, sanctioned welfare recipients maintain a higher search effort after the expiration of the benefits reduction. Furthermore, because the additional search effort generates extra search costs, being unemployed is less preferable, that is, the welfare recipient decreases his reservation wage. Both have a lasting positive effect on $\theta_{u}$. A similar effect could occur if individuals overestimate the extent of monitoring after the imposition of the sanction. These effects may be more relevant for individuals who experience their first welfare spell. 
So far, we assumed that $p(s)$ is constant over the welfare duration. In reality, monitoring is more intense at around 8 months of welfare duration than before that. If individuals only realize this when they are in welfare for 8 months, then this generates a sudden increase in the transition rate from welfare to work. If individuals anticipate the increased monitoring, then $\theta_{u}$ increases more gradually during the first 8 months of welfare. In both cases, $\theta_{u}$ may decrease when monitoring becomes less intense. Of course, there are various other reasons for why $\theta_{u}$ may display positive or negative duration dependence during the first 8 months (and thereafter).

We should emphasize that all these effects concern individuals who are actually at risk of getting a sanction. These may constitute a large or small fraction of a given data set. Moreover, for the individuals at risk, the quantitative effect depends on the structural parameters. If the individual search intensity is close to a physical maximum and the job acceptance probability is almost equal to one, then $\theta_{u}$ is mostly determined by the selection and job offer behavior of employers and by the technology of the matching process. In that case, the effect of a sanction is small.

We should also emphasize that in practice, the above effects may work with a certain lag because of institutional constraints. Notably, there is a time interval between the submission of a successful application letter and the moment at which the individual accepts the job. Also, a job usually starts at the first day of the first or second month after the individual has accepted the job. Finally, as we have seen in Section IIB, there may be some time between the detection of a violation and the starting date of the benefits reduction.

For the empirical model specification it is important to note that $\theta_{u}$ and $\theta_{s}$ depend on the same set of personal characteristics. This is because both depend on the individual's optimal search intensity $s^{*}$, which in turn depends on all determinants of the individual's decision problem (see the equations above). This has an obvious implication for the empirical analysis in case of unobserved heterogeneity among individuals, since it creates a spurious relation between the duration until a sanction arrives and the duration of unemployment (this is the selectivity problem discussed in Sec. I). Note that a similar spurious relation is created if the policy parameters of the sanction rate $p($.$) itself differ across individuals in a way$ that is not observed by the researcher.

\section{B. Empirical Model}

It is useful to start this subsection with a brief outline of the type of data we have. Our database consists of all individuals who started collecting welfare benefits in 1994 in Rotterdam. For each individual we know the precise duration of welfare, unless there was right censoring at the end of the observation period, which is October 1996. We also observe 
the exit destination, which is usually employment. Other possibilities are leaving the municipality, getting married, or stopping to apply for welfare benefits for unknown reasons. Exit to such destinations is treated as independent right censoring of the duration until exit to work. We do not have any information about what happens afterward. For each individual we know whether he was punished with a sanction, and, if so, we know the exact moment of imposition. We also observe the length of the period during which the benefits were reduced, and in most cases we also know the magnitude of benefit reduction. We will only use this additional information in the sensitivity analyses of Section VB.

Consider individuals receiving welfare benefits for $t$ units of time. We assume that differences in transition rates from welfare to work can be characterized by the observed characteristics $x$, the unobserved characteristics $v_{u}$, the elapsed welfare duration itself, and a variable indicating whether a sanction has already been imposed during the spell. We assume $x$ to be constant and $v_{u}$ to be independent of $x$. Let $t_{s}$ be the moment at which a sanction is imposed on the individual and $\mathrm{I}\left(t_{s}<t\right)$ the variable indicating whether a sanction has been imposed $(\mathrm{I}(\cdot)$ is the indicator function).

After imposition, a sanction may be assumed to have a permanent multiplicative effect on the transition rate, which is equal for all types of individuals. In addition, one may abstract from multiple sanctions in a single welfare spell. These assumptions are obviously rather strong, and we relax them in the empirical analysis, although, as we will see, the data impose restrictions on what can be identified.

The transition rate from welfare to work at $t$ conditional on $x, v_{u}$, and $t_{s}$ is denoted by $\theta_{u}\left(t \mid x, v_{u}, t_{s}\right)$ and is assumed to have the familiar Mixed Proportional Hazard (MPH) specification

$$
\theta_{u}\left(t \mid x, v_{u}, t_{s}\right)=\lambda_{u}(t) \exp \left[x^{\prime} \beta_{u}+\delta \cdot \mathrm{I}\left(t_{s}<t\right)+v_{u}\right],
$$

in which $\lambda_{u}(t)$ represents the individual duration dependence. Let $t_{u}$ be the realized duration when leaving to employment. The conditional density function of $t_{u} \mid x, v_{u}, t_{s}$ can be written as

$$
f_{u}\left(t_{u} \mid x, v_{u}, t_{s}\right)=\theta_{u}\left(t_{u} \mid x, v_{u}, t_{s}\right) \exp \left[-\int_{0}^{t_{u}} \theta_{u}\left(z \mid x, v_{u}, t_{s}\right) d z\right] .
$$

For an individual who has received welfare benefits for $t$ units of time and on whom no sanction has been imposed, the sanction rate at $t$ conditional on observed and unobserved characteristics $x$ and $v_{s}$ is denoted by $\theta_{s}\left(t \mid x, v_{s}\right)$ and is also assumed to have the MPH specification

$$
\theta_{s}\left(t \mid x, v_{s}\right)=\lambda_{s}(t) \exp \left(x^{\prime} \beta_{s}+v_{s}\right)
$$

where $x$ is assumed to be constant over time and independent of $v_{s}$. If 
$t_{s}$ denotes the moment of imposing the first sanction, the conditional sanction duration density function of $t_{s} \mid x, v_{s}$ is

$$
f_{s}\left(t_{s} \mid x, v_{s}\right)=\theta_{s}\left(t_{s} \mid x, v_{s}\right) \exp \left[-\int_{0}^{t_{s}} \theta_{s}\left(z \mid x, v_{s}\right) d z\right] .
$$

Now consider the joint distribution of $t_{u}$ and $t_{s}$. Conditional on $x, v_{u}$, and $v_{s}$, the only possible relation between the variables $t_{u}$ and $t_{s}$ is the relation by way of the direct effect of a sanction on the transition rate from welfare to work. In case of independence of $v_{u}$ and $v_{s}$, we would have a standard duration model for $t_{u} \mid x, t_{s}$ in which $\mathrm{I}\left(t_{s}<t\right)$ can be treated as a time-varying regressor that is orthogonal to the unobserved heterogeneity term $v_{u}$. However, if $v_{u}$ and $v_{s}$ are not independent, inference on $t_{u} \mid x, t_{s}$ has to be based on $t_{u}, t_{s} \mid x$. Let $G\left(v_{u}, v_{s}\right)$ be the joint distribution function of the unobserved characteristics $v_{u}, v_{s}$. The joint density function of $t_{u}, t_{s}$ conditional on $x$, equals

$$
f_{u, s}\left(t_{u}, t_{s} \mid x\right)=\int_{v_{u}} \int_{v_{s}} f_{u}\left(t_{u} \mid x, v_{u}, t_{s}\right) f_{s}\left(t_{s} \mid x, v_{s}\right) d G\left(v_{u}, v_{s}\right) .
$$

It is straightforward to derive the individual contributions to the likelihood function from this joint density function (note the recursive nature of the expression in the integral above). The use of a flow sample of welfare spells implies that we do not have any initial conditions problems. The right censoring in the data is exogenous and is therefore solved in a straightforward manner within the hazard rate framework.

The identification of the model framework is proven and discussed at length in Abbring and Van den Berg (2003). They also demonstrate that the model where some welfare recipients are never punished with a sanction (i.e., the sanction duration distribution is defective) is also identified. To provide some intuition, first note that the data can be broken into two parts: (i) a competing risk part for the duration until a welfare recipient either finds a job or gets a sanction imposed, whichever comes first, and (ii) the residual duration from the moment of imposition of a sanction until exit to work. From Heckman and Honoré (1989), it follows that under general conditions the whole model except for $\delta$ is identified from the data corresponding to the competing risk part. Subsequently, $\delta$ is identified from the data corresponding with part ii of the model.

To clarify further what drives the identification of $\delta$, consider individuals who get a sanction at time $t$. The natural control group consists of individuals who are on welfare for the same period of time at $t$ but who have not yet received a sanction. A necessary condition for a meaningful comparison of these groups is that there is some randomization in the sanction assignment at $t$. The duration model framework allows for such 
a randomization because it specifies assignment by way of the rate of imposition of a sanction. In addition, we have to deal with the selection issue that the unobserved heterogeneity distribution is different between the treatment and control groups at $t$. This is handled by exploiting the information in the data on what happened to individuals who received a sanction or left welfare before $t$.

Another way to look at this is to note that the timing of the consecutive events of \{imposition of a sanction\} and \{exit into work\} is informative on the presence of the causal effect of a sanction. If sanctions are often followed very quickly by exit to work, then this indicates a positive treatment effect. The selection effect does not give rise to the same type of quick succession of events.

\section{Parameterization}

For the duration dependence functions and the bivariate unobserved heterogeneity distribution, we take the most flexible specifications used to date. We take both $\lambda_{u}(t)$ and $\lambda_{s}(t)$ to have a piecewise constant specification,

$$
\lambda_{i}(t)=\exp \left[\sum_{j=1,2, \ldots} \lambda_{i j} \mathrm{I}_{j}(t)\right] \quad i=u, s
$$

where $j$ is a subscript for time intervals and $\mathrm{I}_{j}(t)$ are time-varying dummy variables that are one in consecutive time intervals. Note that with an increasing number of time intervals any duration dependence pattern can be approximated arbitrarily closely.

We take the joint distribution of the unobserved heterogeneity terms $v_{u}$ and $v_{s}$ to be bivariate discrete, with two unrestricted mass-point locations for each term. ${ }^{10}$ Let $v_{u}^{a}, v_{u}^{b}, v_{s}^{a}$, and $v_{s}^{b}$ denote the points of support of $v_{u}$ and $v_{s}$, respectively. The associated probabilities are denoted as follows:

$$
\begin{aligned}
& \operatorname{Pr}\left(v_{u}=v_{u}^{a}, v_{s}=v_{s}^{a}\right)=p_{1}, \quad \operatorname{Pr}\left(v_{u}=v_{u}^{b}, v_{s}=v_{s}^{a}\right)=p_{3}, \\
& \operatorname{Pr}\left(v_{u}=v_{u}^{a}, v_{s}=v_{s}^{b}\right)=p_{2}, \operatorname{Pr}\left(v_{u}=v_{u}^{b}, v_{s}=v_{s}^{b}\right)=p_{4},
\end{aligned}
$$

with $0 \leq p_{i} \leq 1$ for $i=1, \ldots, 4$, and $p_{4}=1-p_{1}-p_{2}-p_{3}$.

\footnotetext{
${ }^{10}$ In the empirical analyses we allowed for more mass points. However, during the optimization of the log likelihood function, the locations of the additional mass points converged to each other, and no improvement in the optimal value of the $\log$ likelihood function was found. A more general issue is whether the results are sensitive to the choice of a discrete distribution for unobserved heterogeneity as opposed to a continuous or mixed discrete-continuous distribution. The methodological and empirical literature provides evidence that discrete distributions are sufficiently flexible to capture "random-effects" unobserved heterogeneity (see Van den Berg 2001).
} 
The covariance of $v_{u}$ and $v_{s}$ equals

$$
\operatorname{cov}\left(v_{u}, v_{s}\right)=\left(p_{1} p_{4}-p_{2} p_{3}\right) \times\left(v_{u}^{a}-v_{u}^{b}\right) \times\left(v_{s}^{a}-v_{s}^{b}\right) .
$$

It is easy to show that $v_{u}$ and $v_{s}$ are independent if and only if $\operatorname{cov}\left(v_{u}, v_{s}\right)=0$. Furthermore, the variables $v_{u}$ and $v_{s}$ are perfectly correlated if $p_{1}=p_{4}=0$ or $p_{2}=p_{3}=0$.

\section{The Data}

Our database concerns welfare recipients in Rotterdam, which is the second largest city in the Netherlands. At the end of 1995, Rotterdam had almost 600,000 inhabitants; approximately 260,000 of these people were employed workers. About $40 \%$ of the Rotterdam population consists of immigrants or their children. There were around 35,000 unemployed workers, which is $15 \%$ of the labor force. About 61,000 individuals were receiving some kind of social security benefit. Of these, $78 \%$ had received this benefit already for more than 1 year.

The database contains administrative information on all unemployed individuals who became eligible for welfare, started to collect welfare benefits in Rotterdam in 1994, and were obliged to search for a job. After excluding school leavers, our data set consisted of 8,411 job losers. In addition, we exclude 58 individuals for whom the location of the neighborhood is missing. Finally, we exclude individuals who had a sanction imposed immediately at the start of their welfare spell. The reason is that it is not possible econometrically to identify the selectivity involved in the imposition of sanctions at the start of a spell. Also, sanctions at the start are given for reasons related to behavior before receiving any welfare benefits, which are very different from reasons for sanctions during the spell. It should be stressed that if an unemployed worker who receives UI benefits gets a sanction imposed toward the end of his eligibility period, the sanction is not continued by the welfare agency, not even if the duration of the sanction is not yet expired. The final data set consists of 7,978 individuals.

All information on events is daily. In $25 \%$ of the cases, information on the magnitude of the sanction is missing, but we do not omit these cases. Unfortunately, we cannot identify multiple welfare spells of a single welfare recipient. If a worker experiences more than one spell of welfare starting in 1994, the data do not reveal that these spells are experienced by the same worker. About $2 \%$ of the welfare recipients have been given more than one sanction within a given welfare spell. Figure 1 shows the rate at which welfare recipients move to employment. This rate is highest at the beginning of the welfare period. During the first 6 months, the monthly reemployment probability is approximately $3.5 \%$. After this period, the transition rate to work decreases over the welfare duration. The 


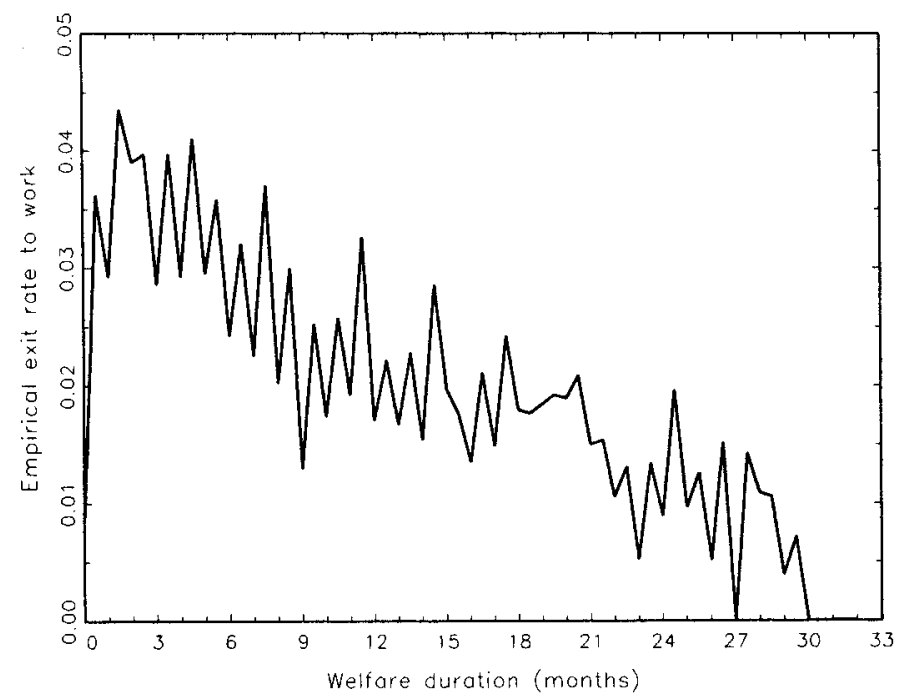

FIG. 1.-Empirical transition rate from welfare to work

sanction rate is shown in figure 2. The sanction rate is highest in the period from 5 months until 1 year, which coincides with the period at which the first thorough investigation takes place (see Sec. IIB). During this period the sanction rate is around $1.5 \%$.

In the analysis we use the values of the explanatory variable $x$ at the moment of inflow. In addition to standard personal characteristics, we include in $x$ a variable indicating whether the individual has ever received welfare benefits before. An individual is considered as being married in case of marriage or cohabitation. The dummy variables "UI received" and "extended UI received" indicate if the unemployed worker entered welfare after his eligibility period for UI expired. The dummy variable "UI received" equals one if the welfare recipient did not receive the extended UI benefits. In this case the individual received UI benefits for 6 months. Extended UI benefits are only provided to unemployed workers who worked 3 of the 5 years previous to unemployment. For those unemployed workers the total UI period always exceeds 6 months (see Abbring et al. [1997] for a more extensive discussion of the UI system in the Netherlands). We do not have information on profession and level of education, because variables that are not relevant for the welfare agency are not included in the database. We include dummy variables for the 12 districts of Rotterdam. The administrative data do not suffer from selective nonresponse or attrition.

Table 1 provides some statistics of the data set. In October 1996, 39\% of our sample has left welfare in order to work. Since some of the welfare 


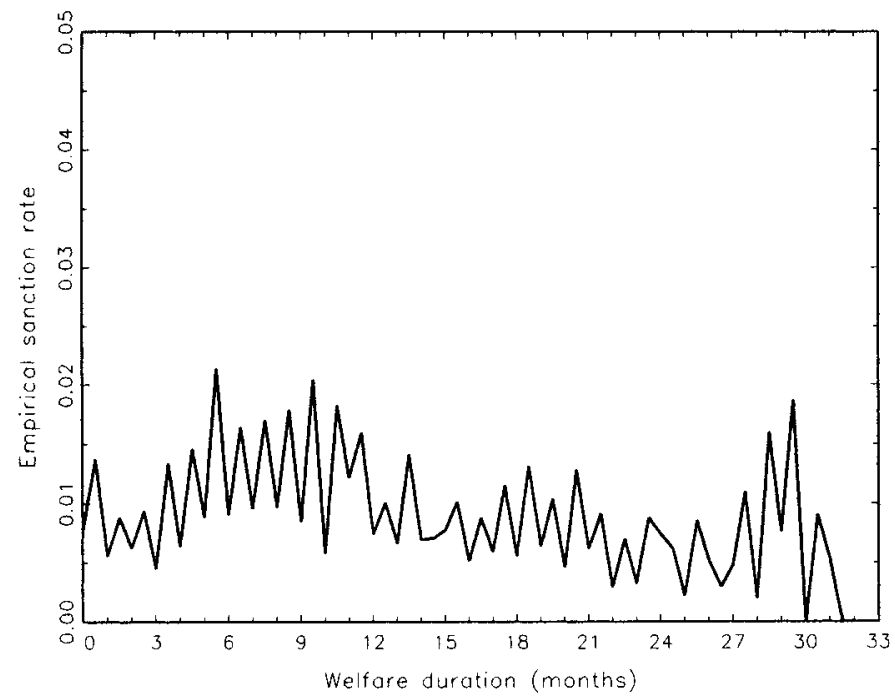

FIG. 2.-Empirical sanction rate

recipients were "exposed to the risk" of leaving the welfare system since January 1994, while others entered in December 1994, it is difficult to draw conclusions from this number. Nevertheless, we can get a first impression of differences among individuals by comparing such probabilities for different groups. The last column of table 1 shows $\chi^{2}$ test statistics for equality in reemployment and sanction probabilities among the subgroups of individuals (all based on one characteristic). The tests basically show that all characteristics are relevant, as we never accept equality. The exit probabilities of youths, females, nonnatives, recurrent recipients, singles, and parents are lower than those of their counterparts. Individuals who collected UI benefits, but not extended UI benefits, previous to welfare, have higher reemployment rates than individuals who either did not collect UI benefits or were eligible for extended UI benefits. About $14 \%$ of the individuals in the sample had a sanction imposed on them. This seems high in comparison with the nationwide annual average of about $5 \%$, but both figures are hard to compare. First, some of the individuals in our sample have been in the welfare system for almost 3 years. Second, our data are collected by sampling from an inflow, while the $5 \%$ figure relates to the stock of welfare recipients. A large part of the stock has been in the welfare system for several years, and their sanction rate may be lower than for the welfare recipients with a short duration. 
Table 1 Some Characteristics of the Data Set

\begin{tabular}{|c|c|c|c|c|c|c|}
\hline \multirow[b]{3}{*}{ Sanction } & \multicolumn{4}{|c|}{ Unemployment Spell } & \multirow[b]{3}{*}{$\begin{array}{c}\text { Total } \\
\text { No. of } \\
\text { Individuals }\end{array}$} & \multirow{3}{*}{$\begin{array}{c}\chi^{2} \text { Test } \\
\text { for } \\
\text { Similarity } \\
\text { (df) }\end{array}$} \\
\hline & \multicolumn{2}{|c|}{$\begin{array}{l}\text { Exits to } \\
\text { Work }\end{array}$} & \multicolumn{2}{|c|}{$\begin{array}{l}\text { Is Right } \\
\text { Censored }\end{array}$} & & \\
\hline & $\begin{array}{l}\text { No } \\
(\%)\end{array}$ & $\begin{array}{l}\text { Yes } \\
(\%)\end{array}$ & $\begin{array}{l}\text { No } \\
(\%)\end{array}$ & $\begin{array}{l}\text { Yes } \\
(\%)\end{array}$ & & \\
\hline \multicolumn{7}{|l|}{ Individual characteristics: } \\
\hline Ages $18-25$ & 43 & 4 & 41 & 12 & 3,249 & $298.6(15)$ \\
\hline Ages $26-35$ & 35 & 3 & 50 & 11 & 2,879 & \\
\hline Ages 36-45 & 26 & 3 & 60 & 11 & 1,210 & \\
\hline Ages 46-55 & 22 & 2 & 67 & 10 & 533 & \\
\hline Ages 56-65 & 8 & 1 & 86 & 5 & 107 & \\
\hline Male & 37 & 4 & 46 & 13 & 5,206 & $93.9(6)$ \\
\hline Female & 34 & 2 & 56 & 8 & 2,772 & \\
\hline Dutch & 39 & 3 & 47 & 10 & 6,034 & $112.5(6)$ \\
\hline Non-Dutch & 26 & 3 & 57 & 14 & 1,944 & \\
\hline Collected welfare before & 34 & 4 & 49 & 14 & 4,399 & $85.1(6)$ \\
\hline New client & 39 & 3 & 50 & 8 & 3,579 & \\
\hline Single, no kids & 38 & 4 & 47 & 11 & 5,735 & $151.7(12)$ \\
\hline Single, with kids & 20 & 3 & 67 & 10 & 807 & \\
\hline Married, no kids & 44 & 3 & 43 & 10 & 506 & \\
\hline Married, with kids & 31 & 4 & 54 & 11 & 930 & \\
\hline No UI received & 35 & 3 & 50 & 11 & 6,064 & $20.0(9)$ \\
\hline UI received & 42 & 4 & 43 & 11 & 929 & \\
\hline Extended UI received & 36 & 3 & 49 & 12 & 985 & \\
\hline \multicolumn{7}{|l|}{ Districts: } \\
\hline Centrum & 35 & 3 & 49 & 13 & 444 & $131.2(36)$ \\
\hline Delfshaven & 34 & 3 & 51 & 12 & 1,695 & \\
\hline Kralingen-Crooswijk & 43 & 3 & 43 & 10 & 879 & \\
\hline Noord & 40 & 3 & 47 & 9 & 805 & \\
\hline Prins Alexander & 45 & 2 & 46 & 8 & 437 & \\
\hline Overschie & 30 & 3 & 48 & 13 & 160 & \\
\hline Hillegersberg-Schiebroek & 44 & 3 & 45 & 7 & 203 & \\
\hline Hoek van Holland & 53 & 9 & 29 & 9 & 34 & \\
\hline Charlois & 36 & 4 & 51 & 11 & 1,065 & \\
\hline Feijenoord & 28 & 4 & 53 & 14 & 1,353 & \\
\hline IJsselmonde & 38 & 1 & 53 & 7 & 493 & \\
\hline Hoogvliet & 37 & 3 & 49 & 11 & 410 & \\
\hline Total & 36 & 3 & 49 & 11 & 7,978 & \\
\hline
\end{tabular}

NotE. - UI = unemployment insurance. Individuals with a certain characteristic are distributed over the four groups defined by whether a transition from welfare to work is observed and whether a sanction is imposed within the observed welfare spell. The total column gives the total number of individuals in the sample with a certain characteristic. The last column on the right gives the $\chi^{2}$-test statistic for equality of the reemployment and sanction fraction across the values of the characteristic. The degrees of freedom of the test statistic are in parentheses.

\section{Estimation Results}

\section{A. Parameter Estimates}

In this section we discuss the results of our empirical analysis. In the current subsection we present the parameter estimates of our baseline model, while in Section VB we perform sensitivity analyses.

We estimate the parameters of our model using the method of maximum 
likelihood. We take the unit of time to be 1 month. Furthermore, we specify the piecewise constant duration dependence in terms of quarters. Thus, we estimate the parameters $v_{u}^{a}, v_{u}^{b}, v_{s}^{a}, v_{s}^{b}, \delta, \lambda_{u, t}(t=1, \ldots, 11)$, $\lambda_{s, t}(t=1, \ldots, 11), p_{1}, p_{2}, p_{3}, \beta_{u}$, and $\beta_{s}$, where both $\beta_{u}$ and $\beta_{s}$ are vectors of 21 parameters. We normalize by taking $\lambda_{u, 1}=\lambda_{s, 1}=0$. Because we do not observe transitions to work with an elapsed duration in welfare in its eleventh quarter, we do not estimate $\lambda_{u, 11}$.

Table 2 presents the parameter estimates of our baseline model. The parameter estimates of $p_{2}$ and $p_{3}$ are on the boundary of the parameter space $\left(p_{2}=p_{3}=0\right)$, which implies that the unobserved heterogeneity components of $\theta_{u}$ and $\theta_{s}$ are perfectly correlated. The computed standard errors of all other parameters are conditional on this. Note that $v_{u}^{a}>v_{u}^{b}$ whereas $v_{s}^{a}<v_{s}^{b}$, so neglecting the endogenous selectivity in the imposition of the sanctions would produce a downward bias in the estimate of $\delta$. We return to this in the next subsection. Taken literally, the estimates of $p_{1}$ and $p_{4}$ imply that for given observed characteristics there are two groups of welfare recipients, which differ substantially in terms of reemployment rate and sanction rate. One group represents $68 \%$ of the welfare recipients who find a job rather quickly and face a small sanction rate. The other group has a reemployment rate that is only $13 \%$ of that in the first group, while the sanction rate is almost six times higher than that in the first group.

The main parameter of interest is $\delta$, which represents the effect of a sanction on the transition rate from welfare to work. The estimated value of $\delta$ is 0.91 and is significantly different from zero. A sanction thus raises the transition rate from welfare to work by more than $140 \%$, so this transition rate more than doubles. Perhaps surprisingly, our estimate is very close to the estimates in Abbring et al. (1997) on sanction effects for UI recipients. ${ }^{11}$ One may argue that a doubling of a small transition rate still gives a small transition rate. However, our estimates do imply that a sanction imposed at a relatively early stage in a welfare spell has a large effect on the probability of becoming long-term dependent on welfare. Consider for example a 25-year-old single Dutch man who lives downtown, experiences his first welfare spell, and did not collect any UI benefits previous to welfare. Suppose that his unobserved characteristics equal the mean values of $v_{u}$ and $v_{s}$ in the inflow, and suppose that exits to destinations other than work are ruled out. If no sanctions are applied, then his probability of leaving welfare within 2 years after inflow is equal to 0.66 . However, if a sanction is imposed on the same individual after 6 months of welfare, then the probability of his leaving within 2 years

\footnotetext{
${ }^{11}$ For example, Abbring et al.'s (1997) $\delta$ estimates are 0.57 for UI recipients in the metal industry and 0.81 for UI recipients in the banking sector; both are significant.
} 
Table 2

Estimation Results of the Baseline Model

\begin{tabular}{|c|c|c|}
\hline & Exit Hazard $\theta_{u}$ & Sanction Hazard $\theta_{s}$ \\
\hline Effect of a sanction: $\delta$ & $.91(.34)$ & \\
\hline \multicolumn{3}{|l|}{ Unobserved heterogeneity: } \\
\hline$v^{a}$ & $-2.76(.14)$ & $-4.96(.49)$ \\
\hline$v^{b}$ & $-4.80(.32)$ & $-3.22(.26)$ \\
\hline$p_{1}$ & $.68(.22)$ & \\
\hline$p_{4}$ & $.32(.10)$ & \\
\hline \multicolumn{3}{|l|}{ Duration dependence: } \\
\hline$\lambda_{1}$ & 0 & 0 \\
\hline$\lambda_{2}$ & $.12(.057)$ & $.25(.10)$ \\
\hline$\lambda_{3}^{2}$ & $-.035(.067)$ & $.41(.10)$ \\
\hline$\lambda_{4}$ & $-.23(.080)$ & $.45(.11)$ \\
\hline$\lambda_{5}^{4}$ & $-.27(.090)$ & $.016(.13)$ \\
\hline$\lambda_{6}$ & $-.33(.10)$ & $-.044(.14)$ \\
\hline$\lambda_{7}$ & $-.27(.11)$ & $.033(.15)$ \\
\hline$\lambda_{8}$ & $-.69(.13)$ & $-.33(.18)$ \\
\hline$\lambda_{9}$ & $-.73(.15)$ & $-.44(.21)$ \\
\hline$\lambda_{10}$ & $-1.17(.21)$ & $.051(.23)$ \\
\hline$\lambda_{11}$ & $\ldots$ & $-1.07(.59)$ \\
\hline \multicolumn{3}{|l|}{ Individual characteristics: } \\
\hline Ages 26-35 & -.35 & $-.28(.076)$ \\
\hline Ages 36-45 & $-.77(.074)$ & $-.41(.10)$ \\
\hline Ages 46-55 & $-1.15(.11)$ & $-.63(.15)$ \\
\hline Ages 56-65 & $-2.26(.34)$ & $-1.47(.43)$ \\
\hline Female & $-.089(.049)$ & $-.69(.089)$ \\
\hline Non-Dutch & $-.64(.059)$ & $.029(.084)$ \\
\hline New client & $.17(.043)$ & $-.58(.079)$ \\
\hline Single, with kids & $-.66(.091)$ & $.13(.13)$ \\
\hline Married, no kids & $.32(.085)$ & $-.32(.15)$ \\
\hline Married, with kids & $.0069(.073)$ & $-.28(.11)$ \\
\hline UI received & $.13(.063)$ & $-.13(.11)$ \\
\hline Extended UI received & $-.091(.067)$ & $.038(.10)$ \\
\hline \multicolumn{3}{|l|}{ Districts: } \\
\hline Delfshaven & $-.093(.10)$ & $.0061(.15)$ \\
\hline Kralingen-Crooswijk & $.26(.11)$ & $-.17(.17)$ \\
\hline Noord & $.16(.11)$ & $-.25(.18)$ \\
\hline Prins Alexander & $.32(.12)$ & $-.46(.21)$ \\
\hline Overschie & $-.16(.18)$ & $.028(.27)$ \\
\hline Hillegersberg-Schiebroek & $.32(.15)$ & $-.39(.27)$ \\
\hline Hoek van Holland & $.67(.35)$ & $.50(.53)$ \\
\hline Charlois & $-.011(.11)$ & $-.035(.16)$ \\
\hline Feijenoord & $-.22(.10)^{\prime}$ & $.15(.15)$ \\
\hline IJsselmonde & $.14(.12)$ & $-.66(.22)$ \\
\hline Hoogvliet & $-.036(.13)$ & $-.079(.20)$ \\
\hline Log likelihood & $-20,685.89$ & \\
\hline$N$ & 7,978 & \\
\hline
\end{tabular}

increases to 0.91 . Now consider a 50 -year-old individual who is otherwise equal. If no sanctions are applied, then his probability of leaving welfare within 2 years after inflow is equal to 0.29. If a sanction is given after 6 months, then this probability increases to 0.54 .

It is thus clear that welfare recipients are sensitive to benefit sanctions. Now recall that the decrease in benefits associated with a sanction is often 
not very large. To see why such a small change in benefits can have a large effect, note that welfare recipients have a very low income level. Most of their benefits are spent on the most elementary needs like housing, clothing, and food. Moreover, given the welfare system, there are no strong incentives for precautionary savings, and given the length of an average welfare spell, there is no scope for consumption smoothing to deal with the shock in income. In sum, the marginal utility level of the welfare recipients may be very high, and this may explain a large change in behavior when a sanction is imposed. Additionally, after the imposition of the sanction, the welfare recipient is more closely monitored. At the same time, the welfare agency will provide more information on how the recipient can search more effectively for a job. Part of the effect of the sanctions may therefore be caused by the counseling and increased monitoring of the welfare agency.

Now let us turn to the covariate effects on $\theta_{u}$. These are all significantly different from zero. The rate is lower for older, non-Dutch, single individuals, and for parents. Those who received UI benefits before have a higher reemployment rate than those who did not receive these benefits or those who received extended UI benefits. However, the differences are small. It is interesting to pay close attention to the household characteristics, as they are closely related to the welfare benefits level. Recall that a household with married members and no children receives much lower per-person benefits than a single individual, so one may actually expect someone in the former household to have a higher $\theta_{u}$ (note that someone who is married to a full-time employed person is in general not entitled to welfare, so he would not be in our data). Now consider the effect of children. Having children increases the benefits level of unmarried recipients, so one may expect this to decrease $\theta_{u}$ (of course, having children may also increase the nonpecuniary utility of being unemployed, and this is an additional reason to expect a lower $\theta_{u}$ ). Note that if the individual is a single parent and one of the children is below 12 years, then he is not obliged to search for a job, so then he is not in our data.

The duration dependence of $\theta_{u}$ is shown in figure 3. Overall, the individual transition rate from welfare to work decreases as the duration increases. (There are slight increases after 3 months and after 18 months.) Apparently, stigmatization and discouraged worker effects play a significant role.

The sanction rate rises during the first year of welfare, which is consistent with the fact that the welfare agency needs some time to gather information on the behavior of the welfare recipient. As indicated before, many welfare recipients have a thorough investigation of their files after 8 months. If there is evidence of noncompliance with job search guidelines, then a sanction will be imposed 1-2 months later. This time pattern is reflected in figure 4, where the sanction rate has a peak at 10-12 months. 


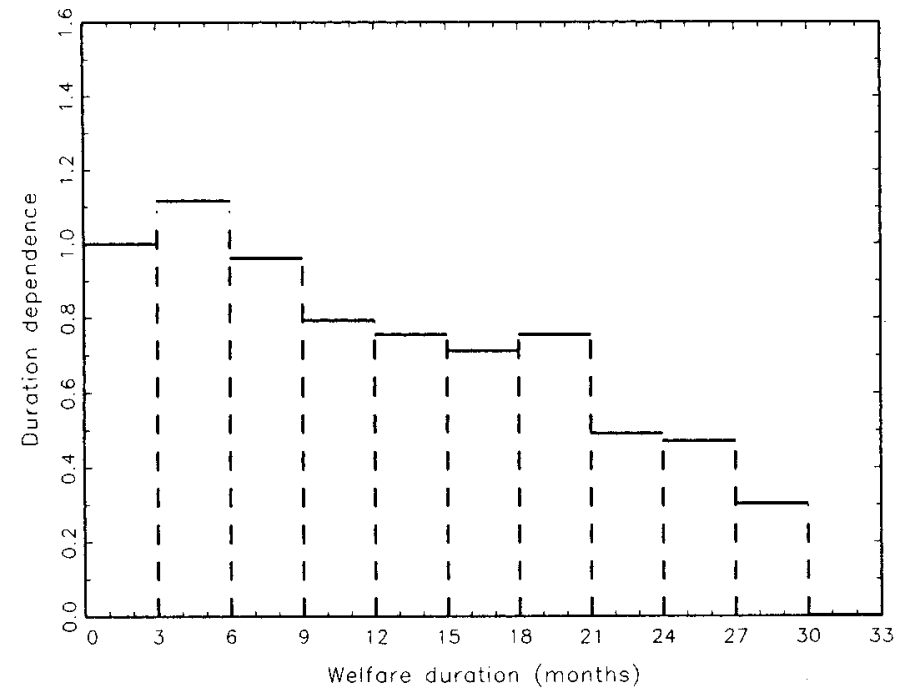

FIG. 3.-The first duration interval is normalized to one. The duration dependence is of the transition rate from welfare to work.

The level is $60 \%$ higher than in the first quarter. After the first year the sanction rate has a downward trend. This suggests that the relevant individuals changed their search behavior. Alternatively, welfare agencies are more tolerant toward long-term unemployed individuals (who have lower exit rates), or at least toward individuals who are categorized in groups with a high expected unemployment duration. The estimates of the covariate effects $\beta_{u}$ and $\beta_{s}$ provide other evidence of such an attitude within the welfare agencies. Age and gender have significant effects on $\theta_{s}$ as well as on $\theta_{u}$, and the signs of the two effects are the same. Again, this may result from a systematic relation in behavior across the two dimensions we consider, along the lines we discussed in Section IIIA. However, it may also indicate that whenever the decision has to be made whether to impose a sanction, the agency takes the expected remaining unemployment duration (or the reemployment rate) of the individual into account. If an individual has a high expected remaining duration (e.g., if the individual is old, female, or long-term unemployed), then the agency may regard a sanction to be less acceptable morally. In such a case, it may be expected that it will be very difficult for the individual to find a job soon anyway, so the individual would have to bear the full weight of the sanction. Recall from Section IIB that field research has provided evidence for this attitude within the welfare agencies. Abbring et al. (1997) find 


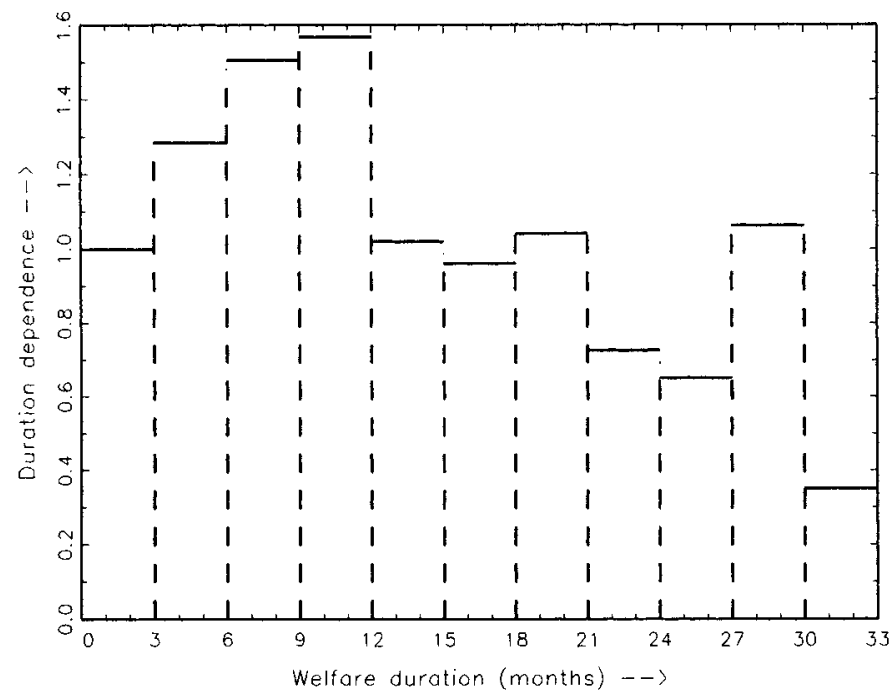

FIG. 4.-The first duration interval is normalized to one. The duration dependence is of the sanction rate.

similar results for UI. From an econometric point of view, this is selectivity from the side of the agency imposing the sanctions.

It should be stressed, though, that this is not the whole story concerning the behavior of welfare agencies. There are two other personal characteristics that have a significant effect on the sanction rate, but these have an opposite effect on the reemployment rate. In particular, married individuals and new welfare recipients have a low sanction rate and a high reemployment rate. These may simply be individuals who have a high search intensity because of certain values of their structural parameters. In addition, new welfare recipients may have lower sanction rates because they do not have a record of past sanctions.

Finally, there are significant differences in sanction rates between the districts. The likelihood ratio (LR) test statistic for the sanction rates being the same across districts equals 37.0. This is consistent with the policy of most municipalities that gives the welfare agencies discretionary power in the process of imposing sanctions (see Sec. IIB). However, the result may also follow from compositional differences of the population of welfare recipients between the districts.

\section{B. Sensitivity Analysis}

In this subsection we examine the sensitivity of the parameter estimates with respect to the model specification. We focus on the estimates of the 
Table 3

Parameter Estimates of the Effect of a Sanction for Different Specifications of the Model

\begin{tabular}{|c|c|c|c|}
\hline & $\begin{array}{l}\text { Sanction } \\
\text { Effect } \delta\end{array}$ & $\begin{array}{c}\text { Log } \\
\text { Likelihood }\end{array}$ & df \\
\hline Independent unobserved heterogeneity & $.0013(.066)$ & $-20,694.35$ & -1 \\
\hline \multicolumn{4}{|l|}{ Effect dependent of individual characteristics: } \\
\hline Intercept & $.38(.36)$ & $-20,675.80$ & +12 \\
\hline Ages 26-35 & $.10(.18)$ & & \\
\hline Ages 36-45 & $.44(.24)$ & & \\
\hline Ages 46-55 & $.26(.40)$ & & \\
\hline Ages 56-65 & $1.52(1.55)$ & & \\
\hline Female & $-.097(.21)$ & & \\
\hline Non-Dutch & $.18(.20)$ & & \\
\hline New client & $.41(.17)$ & & \\
\hline Single, with kids & $.84(.31)$ & & \\
\hline Married, no kids & $-.27(.39)$ & & \\
\hline Married, with kids & $.11(.26)$ & & \\
\hline UI received & $.11(.23)$ & & \\
\hline Extended UI received & $.056(.24)$ & & \\
\hline \multicolumn{4}{|l|}{ Effect different during and after sanction: } \\
\hline During & $.88(.34)$ & $-20,683.43$ & +1 \\
\hline After & $1.32(.35)$ & & \\
\hline \multicolumn{4}{|l|}{ Effect dependent on the magnitude: } \\
\hline $5 \%$ & $.89(.34)$ & $-20,684.97$ & +3 \\
\hline $10 \%$ & $.62(.38)$ & & \\
\hline $20 \%$ & $.86(.40)$ & & \\
\hline Unknown & $.95(.38)$ & & \\
\hline
\end{tabular}

effect of a sanction. The other parameter estimates do not change much from those reported in Section VA. Table 3 reports the parameter estimates for the effect of a sanction for the different model specifications investigated in this subsection.

First of all, we test whether the unobserved heterogeneity terms $v_{u}$ and $v_{s}$ are independent. Under the maintained assumption that both terms are dispersed, the LR test has a $\chi^{2}$ distribution with one degree of freedom under the null hypothesis of independence. The LR test statistic is equal to 19.8 , indicating that, indeed, selectivity in the imposition of sanctions cannot be ignored. Note that in the restricted model we do not find any unobserved heterogeneity in the sanction rate or the reemployment rate. More important, neglecting the (negative) relation between the unobservable components leads to underestimating the effect of a sanction. Indeed, the sanction effect becomes insignificant. This again shows the importance of taking selectivity into account.

We also perform sensitivity analyses with respect to the model specification of the sanction effect. First, we allow the effect $\delta$ of a sanction to vary over the population by specifying $\delta=\delta(x)=x^{\prime} \gamma$. The vector $x$ includes an intercept and all explanatory variables used before, except for 
the district indicators, as the number of sanctions per district is rather low. The LR test statistic on joint significance of all elements of $\gamma$ is equal to 20.2. Since we have 12 additional parameters, we cannot reject the null hypothesis that the sanction effect is independent of individual characteristics, at the $5 \%$ level. Taken in isolation, some individual characteristics have a significant effect on the effect of sanctions, which is actually in agreement with the theoretical model framework (see Sec. IIIA). In particular, the dummy variable for "new client" and the household composition variables have significant coefficients. The sanction effect is larger for new clients and single welfare recipients with children. It might be that new clients have less information about the seriousness of the sanction regime and the actual job search requirement of the welfare agency than do recurrent welfare recipients and, therefore, increase their job search effort more because of the closer monitoring and additional counseling of the welfare agency after the imposition of a sanction. Single welfare recipients with children seem to be a special group, as these individuals have relatively low reemployment rates, the highest sanction rates, and are obviously also very sensitive to sanctions. It seems that these individuals display lower job search effort. Therefore, they have a large risk of getting a sanction imposed, and once a sanction has been imposed they have to increase their search effort much more than other welfare recipients to comply with the welfare agency's guidelines.

So far we have assumed that once a sanction is imposed, it has a permanent effect on the transition rate to work. We relax this assumption by allowing the effect after the expiration of the benefits reduction to differ from the effect during the period of benefits reduction. Letting $t_{s}$ be the moment at which the sanction is imposed and $t_{e}$ the moment at which the benefits reduction ends, we specify $\delta$ as $\delta=\delta_{1} \cdot \mathrm{I}\left(t_{s}<t \leq\right.$ $\left.t_{e}\right)+\delta_{2} \cdot \mathrm{I}\left(t_{e}<t\right)$. The duration $t_{e}-t_{s}$ of the benefits reduction differs across sanctions (see Sec. IIB), but in most cases it equals 1 month (602 cases) or 2 months (541 cases). It exceeds 2 months in only 13 cases. $^{12}$ Using a LR test, we reject the null hypothesis that $\delta_{1}=\delta_{2}$. In fact, the effect after the expiration of the benefits reduction is somewhat larger than that during the period of the reduction. At first sight this seems puzzling from a theoretical point of view. After all, the benefits level increases on expiration, and the search intensity is not expected to increase at that moment (see Sec. IIIA). An explanation is that in reality it takes some time before the adjusted job search behavior becomes effective after the imposition of a sanction. In general, the process of hiring an individual

\footnotetext{
${ }^{12}$ It should be stressed that we neglect any selectivity involved in the choice of a particular duration of the sanction. In reality, this duration depends on the reason for imposition of the sanction. Welfare recipients who are confronted with a long duration $t_{e}-t_{s}$ may be different from those with a short duration.
} 
takes time because of job interviews and firms' administrative obligations. This implies that there is some time lag between the moment at which the unemployed worker increases his job search effort and the moment his reemployment rate increases. It is not exceptional that this lag is 1 or 2 months, which is also the duration of benefits reduction $t_{e}-t_{s}$. This may imply that most of the increase in transition rate to work occurs after expiration. In addition, the additional job search assistance only starts after the sanction has been imposed, and this may also cause a lag. Finally, the increased monitoring often only starts some months after the imposition of the sanction. ${ }^{13}$

The empirical model of Section IIIB does not take into account that the amount of benefits reduction differs across sanctions. We observe 669 sanctions with a 5\% reduction, 207 with $10 \%, 133$ with $20 \%$, and 147 sanctions where information on the magnitude is missing. The magnitude depends on the reason for the imposition of the sanction, so it is plausible that it is related to $v_{\mu}$. We ignore this additional selection problem, for the simple reason that we cannot correct for it. Basically, we use all available information to deal with the selectivity in the moment at which a sanction is imposed, and there is no additional information to deal with the selectivity in the magnitude. We therefore estimate a model that differs from the basic model merely because $\delta$ now depends on the magnitude of the benefits reduction. Specifically, let $\delta_{m}$ be the effect in case of a reduction of $m \%, m=5,10,20$, and $\delta_{n}$ the effect of a sanction where the magnitude is missing in the database. The LR test does not reject the null hypothesis that $\delta=\delta_{m}$ for all $m=5,10,20, n$.

The sensitivity analyses above indicate that the effect of a sanction is not restricted to the period of benefits reduction. Furthermore, the amount of benefits reduction seems to be unimportant for the sanction effect. This could be taken as evidence that any pecuniary incentive of a sanction is dominated by nonpecuniary factors, setting aside for the mo-

\footnotetext{
${ }^{13}$ We also estimated a model extension in which $\delta$ is specified as a flexible piecewise-constant function of the elapsed duration $t-t_{s}$ since imposition of the sanction. This specification does not take account of the expiration time, but it does allow the sanction effect to diminish slowly as time proceeds. The estimation results (not presented here) are as follows: the estimated unobserved heterogeneity distribution is basically such that either one never gets a sanction and has a reasonably high transition rate from welfare to work, or one has a high rate of getting a sanction, and the transition rate from welfare to work is almost zero. The estimated direct sanction effect is estimated to be extremely high for all values of $t-t_{s}$. As a result, the second subgroup of individuals only leaves unemployment after imposition of a sanction. These estimation results are very implausible. It can be argued that this specification asks too much from the data. Note that this, in turn, suggests some caution interpreting the results when allowing for different sanction effects during and after imposition.
} 
ment the objection that the results above can be affected by selectivity. ${ }^{14}$ However, a permanent effect works by way of an increased search intensity, and this most likely results from the combination of increased monitoring and the threat of a severe punishment when recidivism is detected. Because of the latter, it could be argued that a permanent effect at least partly results from financial incentives. Moreover, the insensitivity of the transition rate to work with respect to the exact amount of benefits reduction can also be explained if even a small decrease in welfare benefits causes the individual to increase his search effort up to a physical maximum.

Now let us turn to sensitivity analyses concerning the labor-market states before and after welfare. First of all, recall from Section 2A that we restrict attention to welfare recipients who once lost a job, excluding school leavers on welfare. However, the estimation of the model with the joint data on both types of welfare recipients does not affect the major conclusions. In particular, the estimate of $\delta$ is 0.63 (standard error 0.25 ), so it is significantly positive and only marginally smaller than in table 2 . The number of observed sanctions for school leavers is too small to estimate the full model separately for that group (some parameters could not be estimated).

Concerning the destination states, recall that we treat exit to other destinations than work as independent right censoring of the duration until exit to work. Relaxing this (e.g., by postulating a competing-risks model with potentially related unobserved heterogeneity terms for each destination) would result in estimates that are very sensitive to functionalform assumptions. Therefore, we estimate the same model focusing on all exits from welfare, that is, we include exits because of marriage, leaving the municipality, and stopping to apply for welfare benefits for unknown reasons in the transitions out of welfare. The estimated effect of a sanction is slightly lower but still significant, 0.73 (with a standard error of 0.23 ). ${ }^{15}$

${ }^{14}$ This would be in line with Fortin, Lacroix, and Drolet (2003), who find for Canada that the level of welfare benefits has a negative but small effect on the individual transition rate from welfare to work. A similar result for the United States is found by Hoynes and MaCurdy (1994), who use variation in the welfare benefits level over calendar time to estimate the impact of the benefits level on the welfare duration.

${ }^{15}$ In addition, we have modeled each transition rate to a destination state by way of an MPH specification, where we allow each rate to depend on whether a sanction has been imposed. We impose independence of the unobserved heterogeneity terms, i.e., the unobserved heterogeneity terms are not related to the unobserved heterogeneity terms in the sanction process. It turns out that sanctions do not have a significant effect on exit to the other destinations, except for stopping to apply for welfare benefits for unknown reasons. This suggests that some welfare recipients stop collecting welfare benefits after imposition of a sanction, possibly because they have alternative sources of income and are afraid of becoming accused of fraud. Alternatively, some welfare recipients may leave the municipality on imposition of a sanction, possibly to try to collect benefits in another municipality. 


\section{Conclusions}

In the Netherlands, welfare recipients often stay unemployed for a long period of time, even though they are obliged to comply with guidelines by the welfare agency on search effort. Recipients who do not comply with these or with other rules set by the agency may have a sanction imposed, that is, their benefits may be temporarily reduced. In the empirical analysis on the effects of benefit sanctions one has to allow for selectivity in the imposition of benefit sanctions. We find that there is indeed such selectivity. Conditional on observed characteristics and elapsed duration, welfare recipients with a lower reemployment rate experience a higher sanction rate. After correcting for this selectivity, the imposition of a sanction has a significant positive effect on the transition rate from welfare to work. Indeed, this transition rate is about twice as large after a sanction than before. This estimate turns out to be very close to estimates reported elsewhere on sanction effects for UI recipients. A sanction that is imposed at a relatively early stage in a welfare spell thus has a substantial negative effect on the probability of an individual becoming long-term dependent on welfare.

This result establishes that the system of benefit sanctions affects the behavior of welfare recipients. The benefit sanction itself is temporary, but the effects are long lasting. Even after the sanction period expires, the transition rate from welfare to work is higher than it was before the sanction was imposed. Apparently, marginal utility levels of welfare recipients are so high, or consumption smoothing is so difficult, that a relatively small sanction (and the threat of an additional severe punishment in case of recidivism) can have a large effect on search behavior. Closer monitoring and counseling by the welfare agency, which accompanies the imposition of a sanction, may also have a positive effect on the job search behavior of welfare recipients.

From the theoretical analysis it follows that individuals are expected to have a higher transition rate to work in a system with sanctions even though they have not (yet) been given a sanction. The estimated sanction effect is basically a lower bound of the overall effect of a welfare system with sanctions vis-à-vis a system without sanctions. To quantify the "ex ante" effect of a system with sanctions, we would need to have additional data from a period with a welfare system without sanctions. Alternatively, we would need sufficient information to estimate a structural job search model.

\section{References}

Abbring, Jaap H., and Gerard J. van den Berg. 2003. The non-parametric identification of treatment effects in duration models. Econometrica 71 (September): 1491-1517. 
Abbring, Jaap H., Gerard J. van den Berg, and Jan C. van Ours. 1997. The effect of unemployment insurance sanctions on the transition rate from unemployment to employment. Working paper, Tinbergen Institute, Amsterdam.

Angenent, F. J. A., Y. B. Bommeljé, and G. J. Schep. 1993. Prikkels in de bijstand (Incentives in welfare). The Hague: VUGA Uitgeverij.

1994. Van bijstand naar baan: Over de positie op de arbeidsmarkt en de uitstroom naar werk van cliënten in de ABW-sec/RWW (From welfare to work: About the position in the labor market and the outflow to work for welfare recipients). The Hague: VUGA Uitgeverij.

Angenent, F. J. A., and J. den Heeten. 1995. Straf of stimulans? Het toepassen van sancties als arbeidsmarktinstrument in de RWW (Punishment or incentive? The application of sanctions as a labor-market instrument in welfare). The Hague: VUGA Uitgeverij.

Ashenfelter, Orley, David Ashmore, and Olivier Deschênes. 2003. Do unemployment insurance recipients actively seek work? Randomized trials in four U.S. states. Journal of Econometrics (in press).

Bonnal, Lilaine, Denis Fougère, and Anne Sérandon. 1997. Evaluating the impact of French employment policies on individual labour market histories. Review of Economic Studies 64 (October): 683-713.

Devine, Theresa J., and Nicholas M. Kiefer. 1991. Empirical labor economics: The search approach. Oxford: Oxford University Press.

Dolton, Peter, and Donal O'Neill. 1996. Unemployment duration and the restart effect: Some experimental evidence. Economic Journal 106 (March): 387-400.

Fortin, Bernard, Guy Lacroix, and Simon Drolet. 2003. Welfare benefits and the duration of welfare spells: Evidence from a natural experiment in Canada. Journal of Public Economics (in press).

Gorter, Cees, and Guyonne R. J. Kalb. 1996. Estimating the effect of counseling and monitoring the unemployed using a job search model. Journal of Human Resources 31 (Summer): 590-610.

Gritz, R. Mark. 1993. The impact of training on the frequency and duration of employment. Journal of Econometrics 57 (May-June): 21-51.

Gueron, Judith M. 1990. Work and welfare: Lessons on employment programs. Journal of Economic Perspectives 4 (Winter): 79-98.

Heckman, James J., and Bo E. Honoré. 1989. The identifiability of the competing risk model. Biometrica 76 (June): 325-30.

Hoynes, Hilary, and Thomas MaCurdy. 1994. Has the decline in benefits shortened welfare spells? American Economic Review Papers and Proceedings 2 (May): 43-48.

Meyer, Bruce D. 1995. Lessons from the U.S. unemployment insurance experiments. Journal of Economic Literature 33 (March): 91-131.

Moffitt, Robert. 1992. Incentive effects of the U.S. welfare system: A review. Journal of Economic Literature 30 (March): 1-61. 
Mortensen, Dale T. 1986. Job search and labor market analysis. In Handbook of Labor Economics, vol. 2, ed. O. Ashenfelter and R. Layard. Amsterdam: North-Holland.

OECD (Organization for Economic Cooperation and Development). 1997. Making work pay: Taxation, benefits, employment and unemployment. Paris: OECD.

Van Andel, H. G., and Y. B. Bommeljé. 1996. In en uit de bijstand (Into and out of welfare). The Hague: VUGA Uitgeverij.

Van den Berg, G. J. 2001. Duration models: Specification, identification, and multiple durations. In Handbook of Econometrics, vol. 5, ed. J. J. Heckman and E. Leamer. Amsterdam: North-Holland. 